\title{
Abraham Geiger-skeptischer Pionier einer Glaubenslehre des Reformjudentums?
}

Die Wissenschaft des Judentums brachte sich seit den 1820er Jahren zunächst vor allem im deutschsprachigen Raum in Stellung, wo sie mit autoritativem Anspruch als neues Deutungsmodell jüdischer Religion, Geschichte und Kultur auftrat, die sie mit dem methodischen Rüstzeug der Philologie, Historiographie und Philosophie zu erschließen suchte. ${ }^{1}$ Die Genese und Entwicklung einer an akademischen Standards ausgerichteten jüdischen Forschung bezeichnete einen Paradigmenwechsel gegenüber den Auslegungstraditionen der Vormoderne, in denen sich das Judentum als sinnvermittelndes Handlungssystem präsentiert hatte, das auf der Grundlage einer ewig gültigen göttlichen Selbstmitteilung fußte. In einem programmatischen Aufsatz hatte Leopold Zunz (1794-1886), profilierter Wegbereiter einer kritischen jüdischen Gelehrsamkeit, bereits 1818 die Parole ausgegeben, dass

die ganze Litteratur der Juden, in ihrem größten Umfang, als Gegenstand der Forschung aufgestellt [werden solle], ohne uns darum zu kümmern ob sämmtlicher Inhalt auch Norm für unser eigenes Urtheilen sein soll oder kann. ${ }^{2}$

Die Wissenschaft des Judentums sollte also über etwaige sakrale Geltungsansprüche der Texte hinwegsehen, denen vielmehr als Zeugnissen geistiger Produktivität Aufmerksamkeit zuteil wurde. Von dieser Perspektive aus betrachtet, konnte Gott weder Gegenstand der wissenschaftlichen Untersuchung sein noch ihm die Urheberschaft

Dieser Aufsatz präsentiert Ergebnisse von Forschungen, die ich 2014-2015 als Charles W. and Sally Rothfield Fellow am Herbert D. Katz Center for Advanced Judaic Studies, University of Pennsylvania, Philadelphia, und 2017-2018 als Fellow am Maimonides Centre for Advanced Studies-Jewish Scepticism an der Universität Hamburg durchführen konnte. Für eine kritische Durchsicht des Textes danke ich Michael A. Meyer, Cincinnati.

1 Zur Wissenschaft des Judentums vgl. z. B. die Sammelbände: Kurt Wilhelm, Hrsg., Wissenschaft des Judentums im deutschen Sprachbereich. Ein Querschnitt, 2 Bde. (Tübingen: Mohr, 1967); Julius Carlebach, Hrsg., Wissenschaft des Judentums. Anfänge der Judaistik in Europa (Darmstadt: Wissenschaftliche Buchgesellschaft, 1992); Ismar Schorsch, From Text to Context: The Turn to History in Modern Judaism (Hanover und London: Brandeis University Press, 1994); Michael Brenner und Stefan Rohrbacher, Hrsg., Wissenschaft vom Judentum. Annäherungen nach dem Holocaust (Göttingen: Vandenhoeck \& Ruprecht, 2000); Thomas Meyer und Andreas Kilcher, Hrsg., Die „Wissenschaft des Judentums". Eine Bestandsaufnahme (Paderborn: Wilhelm Fink, 2015).

2 Leopold Zunz, Etwas über die rabbinische Literatur, nebst Nachrichten über ein altes bis jetzt ungedrucktes hebräisches Werk (Berlin: In der Maurerschen Buchhandlung, 1818), 5. 
des kulturellen Erbes zugeschrieben werden, das vielmehr als menschlich Gestaltetes und sich in der sowie durch die Geschichte Veränderndes zum Vorschein trat. ${ }^{3}$

Unbeschadet ihrer betont überlieferungskritischen Ambitionen entwickelte sich die jüdische Forschung aber durchaus nicht als „unabhängig von jüdischen Bindungen zu betreibende, säkulare Disziplin“, sondern entfaltete sich im Laufe des zweiten Jahrhundertdrittels vornehmlich als bekenntnisgebundene Wissenschaft, in der das ergebnisoffene Erkenntnisstreben in einem konstanten Spannungsverhältnis zu den systematisch-normativen Ansprüchen der Religionsgemeinschaft verblieb. ${ }^{4}$ Insofern die jüdische Religion sowohl den objektiven als auch den subjektiven Referenzrahmen der Wissenschaft des Judentums bezeichnete, beabsichtigte diese keine antiquarische Vermessung der Vergangenheit, sondern definierte sich als interessengeleitete ,jüdische Theologie“, als positive Wissenschaft des jüdischen Glaubens in Geschichte und Gegenwart, die an die religiöse Orientierungskrise einer zunehmend mit den Herausforderungen der Moderne konfrontierten Minderheit anknüpfte. Zeugte die jüdische Wissenschaft ${ }^{5}$ von der produktiven Teilhabe von Juden an den allgemeinen Wissenschaftsbestrebungen, die sich freilich weitgehend außerhalb der Hochschulen unter staatlicher Aufsicht entfalten musste, so zielte die Wissensproduktion nicht zuletzt auch auf eine defensive Modernisierung jüdischer Religion, die als bürgerliche Konfession ihren Platz in der Gesellschaft einforderte. ${ }^{6}$

Keine Geschichte der Wandlungen der Wissenschaft des Judentums im 19. Jahrhundert ließe sich erzählen, ohne hierin Abraham Geiger (1810 - 1874) einen prominenten Platz einzuräumen. Dass Geiger, Rabbiner zunächst in Wiesbaden, dann in Breslau, Frankfurt am Main und Berlin, zum Namenspatron des 1999 eröffneten Potsdamer Rabbinerkollegs avancierte, lässt erahnen, welches Ansehen er als Schrittmacher und Meisterdenker einer progressiven Theologie des Judentums noch

3 Vgl. dazu z. B. Leon Wieseltier, „Etwas über die jüdische Historik: Leopold Zunz and the Inception of Modern Jewish Historiography“, in History and Theory 20 (1981): 135-149; Richard S. Sarason, „Rabbinic Literature, Rabbinic History, and Scholarly Thinking: Wissenschaft and Beyond“, in Modern Judaism and Historical Consciousness: Identities-Encounters-Perspectives, hrsg. von Andreas Gotzmann und Christian Wiese (Leiden: Brill, 2007): 93; Nils Roemer, Jewish Scholarship and Culture in NineteenthCentury Germany: Between History and Faith (Madison, Wis.: University of Wisconsin Press, 2005), 24; Christoph Schulte, „Kritik und ,Aufhebung“ der rabbinischen Literatur in der frühen Wissenschaft des Judentums“, in „Im Vollen Licht der Geschichte“. Die Wissenschaft des Judentums und die Anfänge der kritischen Koranforschung, hrsg. von Dirk Hartwig, Walter Homolka, Michael Marx und Angelika Neuwirth (Würzburg: Ergon-Verlag, 2008), 102.

4 Vgl. Christian Wiese, Wissenschaft des Judentums und protestantische Theologie im wilhelminischen Deutschland. Ein Schrei ins Leere? (Tübingen: Mohr Siebeck, 1999), XI.

5 Der in der Literatur des 19. Jahrhunderts weit verbreitete Terminus ,jüdische Wissenschaft“ wird in diesem Aufsatz synonym zum Begriff „Wissenschaft des Judentums“ verwendet.

6 Vgl. auch Michael A. Meyer, „Two Persistent Tensions in Wissenschaft des Judentums“, in Modern Judaism 24.2 (2004): 105-110. Zum Begriff der bürgerlichen Konfession(alität) vgl. Andreas Gotzmann, „Zwischen Nation und Religion: Die deutschen Juden auf der Suche nach einer bürgerlichen Konfessionalität“, in Juden, Bürger, Deutsche. Zur Geschichte von Vielfalt und Differenz 1800-1933, hrsg. von Andreas Gotzmann, Rainer Liedtke und Till van Rahden (Tübingen: Mohr Siebeck, 2001): 241-261. 
heute bzw. heute wieder genießt. ${ }^{7}$ Aber bereits liberale Zeitgenossen und die ältere Historiographie erkannten Geiger als Speerspitze einer gelehrten Avantgarde, deren Forschung nicht nur die Vergangenheit abbildete, sondern auch auf eine Neugestaltung der Gegenwart und Zukunft zielte. ${ }^{8}$ Dieser Aufsatz will Abraham Geigers Bedeutung als Pionier einer jüdischen Theologie auf wissenschaftlicher Basis nicht grundsätzlich neu bewerten, nimmt dessen Werk aber vor allem im Kontext der Suche nach einer systematischen Theologie in den Blick. Die zeitgenössische Sehnsucht nach einer methodisch reflektierten Darstellung des Glaubensinhalts des Judentums durchzieht die deutsch-jüdische Publizistik des 19. und frühen 20. Jahrhunderts. ${ }^{9}$ Die Untersuchung unternimmt es deshalb vor allem, danach zu fragen, inwieweit und in welcher Form Geigers Schriften diesem Bedürfnis nach Orientierung im Glauben Rechnung trugen.

Wie unscharf sich das Bild in dieser Hinsicht bislang präsentiert, veranschaulicht wiederum eine Durchsicht der älteren Geschichtsschreibung. 1910 erschien die als Sammelband konzipierte Biographie Geigers, die sein Sohn Ludwig (1848-1919) unter Mitwirkung namhafter liberaler Rabbiner anlässlich des 100. Geburtstags des Vaters herausgab. Hier unternahm es Heinemann Vogelstein (1841-1911), langjähriger Vorsitzender der Vereinigung der liberalen Rabbiner, in einem mehr als dreißigseitigen Beitrag, Abraham Geiger nicht nur als den ,wissenschaftliche[n] Theologe[n] des neunzehnten Jahrhunderts“ zu bestätigen, sondern ihm auch als dem „Begründer der systematischen Theologie“ ein Denkmal zu setzen. Dass Kaufmann Kohler (18431926), Präsident des Hebrew Union College in Cincinnati (Ohio), wenige Monate zuvor seinen Grundriss einer systematischen Theologie des Judentums auf geschichtlicher Grundlage publiziert hatte, die Vogelstein zudem als erste „zusammenhängende, von einem jüdischen Gelehrten bearbeitete Darstellung des Glaubensinhaltes der jüdischen Religion“ würdigte, liefert aber bereits Anhaltspunkte, dass Geigers Beitrag zur

7 Informationen zum Abraham Geiger Kolleg an der Universität Potsdam: http://www.abraham-gei ger-kolleg.de (Datum); siehe auch Jakob J. Petuchowski, Hrsg., New Perspectives on Abraham Geiger, An HUC-JIR Symposium (New York: Ktav Publishing House, 1975); Christian Wiese, Walter Homolka und Thomas Brechenmacher, Hrsg., Jüdische Existenz in der Moderne. Abraham Geiger und die Wissenschaft des Judentums (Berlin und Boston: de Gruyter, 2013).

8 Sigismund Stern, Geschichte des Judenthums von Mendelssohn bis auf die Gegenwart. Nebst einer einleitenden Überschau der älteren Religions- und Kulturgeschichte (Frankfurt am Main: Rütter, 1857), 232; Leopold Löw, „Literarische Anzeige zu Geigers Urschrift“, in Ben Chananja 1 (1858): 93 f.; Emanuel Schreiber, Abraham Geiger als Reformator des Judenthums (Loebau: R. Skrezeczek, 1879); „Rede des Dozenten Dr. Ismar Elbogen“, aus „Reden bei der Abraham Geiger-Feier der Lehranstalt für die Wissenschaft des Judentums am 22. Mai 1910“, in Neunundzwanzigster Bericht der Lehranstalt für die Lehranstalt für die Wissenschaft des Judentums in Berlin (Berlin: H. Itzkowski, 1911): 54; Caesar Seligmann, Geschichte der jüdischen Reformbewegung von Mendelssohn bis zur Gegenwart (Frankfurt am Main: Kauffmann, 1922), 91-94; vgl. außerdem Wiese, Hrsg., Jüdische Existenz in der Moderne; Imke Stallmann, Abraham Geigers Wissenschaftsverständnis. Eine Studie zur jüdischen Rezeption von Friedrich Schleiermachers Theologiebegriff (Frankfurt am Main: Lang, 2013).

9 Vgl. Hans-Joachim Schoeps, Jüdischer Glaube in dieser Zeit. Prolegomena zur Grundlegung einer systematischen Theologie des Judentums (Berlin: Philo Verlag, 1932). 
systematischen Theologie sich einer pauschalisierenden Einordnung entzog. ${ }^{10}$ Dass es eben nicht möglich war, Texte zu benennen, in denen schon Geiger eine umfassende Glaubens- und Sittenlehre des Judentums in geordneter Form präsentiert hätte, musste auch Vogelstein einräumen. ${ }^{11}$

Auch ein Blick auf seinen Sohn, Rabbiner Hermann Vogelstein (1870 - 1942), bestätigt diese Wahrnehmung einer Uneindeutigkeit: Bekräftigte er als Mitarbeiter an der Sammelbiographie noch die Sicht seines Vaters, indem er den Theologen Geiger ebenfalls als Systematiker vorstellte, so fiel sein Urteil 1927 nachdenklicher aus. Mit der Einschätzung, dass eine jüdische Theologie immer noch ein dringendes Desideratum der Gegenwart bezeichne, gab er jetzt der Überzeugung Ausdruck, dass Geiger mit dem Prinzip der geschichtlichen Entwicklung lediglich die methodischen Grundlagen einer wissenschaftlichen Theologie entwickelt, er aber „so recht eigentlich nicht die theologischen Inhalte“ herausgearbeitet habe. ${ }^{12}$ Seither hat die Geigerforschung diesen Faden nicht wieder aufgenommen. Es lohnt sich aber, der Ambivalenz in Geigers Oeuvre nachzuspüren, zumal, wenn man vermutet, dass sie nicht dem Zufall geschuldet ist, sondern sich aus dem religiösen Weltbild herleiten lässt und als spezifische Antwort des Theologen Geiger auf die Moderne zu verstehen ist. ${ }^{13}$ Es gilt mithin sowohl danach zu fragen, welche Funktion und Bedeutung Abraham Geiger der systematischen Theologie zumaß, als auch zu untersuchen, welchen Platz diese Disziplin in seiner eigenen Forschungsagenda einnahm, um „die jüdische Welt sich selbst vorstellig zu machen“ (Eduard Gans).

10 Heynemann [sic] Vogelstein, „Systematische Theologie“, in Abraham Geiger. Leben und Lebenswerk, hrsg. von Ludwig Geiger (Berlin: Reimer, 1910), 243-276; vgl. Kaufmann Kohler, Grundriss einer systematischen Theologie des Judentums auf geschichtlicher Grundlage (Leipzig: Fock, 1910); englisch: Jewish Theology. Systematically and Historically Considered (New York: Macmillan, 1918).

11 Dass es Rabbiner Ludwig Philippson (1811-1889) war, der anknüpfend an die Offenbarungstexte sowie auf der Grundlage der Geschichte Glaube und Ethik des Judentums für ein gebildetes bürgerliches Publikum systematisch zusammenfasste, ist in der jüdischen Geschichtsschreibung bislang noch nicht ausreichend gewürdigt worden; siehe Ludwig Philippson, Jüdische Religionslehre, 3 Bde. (Leipzig: Baumgärtner, 1861-1865); vgl. „Rede des Dozenten Dr. I. Elbogen bei der Ludwig PhilippsonFeier der Lehranstalt für die Wissenschaft des Judentums am 8. Januar 1912“, in Dreissigster Bericht der Lehranstalt für die Wissenschaft des Judentums (Berlin: H. Itzkowski, 1912), 63; Andreas Brämer, „Überlegungen zur Gebietsmarkierung der Wissenschaft des Judentums-Das Beispiel Ludwig Philippson als zentrale Randfigur (1811-1889)“, in Judaica 74.1-2 (2018): 1-22.

12 Hermann Vogelstein, „Der Theologe. Einleitung“, in Abraham Geiger, hrsg. von Geiger, 235; idem, „Gotteserkenntnis. Eine theologische Skizze“, in Festschrift zum 70. Geburtstage von Moritz Schaefer. Zum 21. Mai 1927 herausgegeben von Freunden und Schülern (Berlin: Philo-Verlag, 1927): 258. Es sei an dieser Stelle auch angemerkt, dass der Religionshistoriker Hans-Joachim Schoeps (1909-1980) in seiner Dissertation Jüdischer Glaube in dieser Zeit Abraham Geiger unerwähnt lässt.

13 Vgl. Michael A. Meyer, Antwort auf die Moderne. Geschichte der Reformbewegung im Judentum (Wien, Köln und Weimar: Böhlau, 2000); Zur Vernachlässigung der Metaphysik durch die Wissenschaft des Judentums vgl. Zeev Falk, ,Jüdisches Lernen und die Wissenschaft des Judentums“, in Judentum im deutschen Sprachraum, hrsg. von Karl E. Grözinger (Frankfurt am Main: Suhrkamp, 1991): 350. 
Die zeitgenössischen Benennungen Wissenschaft des Judentums ${ }^{14}$ oder jüdische Wissenschaft suggerieren zunächst eine homogene Geschlossenheit, die dem methodischen und konzeptuellen Facettenreichtum der Disziplin nicht ausreichend Rechnung trägt. Das verdeutlichen die Entwicklungen insbesondere im zweiten Drittel des 19. Jahrhunderts, als sich die jüdische Forschungslandschaft signifikant vervielfältigte und nicht zuletzt Rabbiner mit Universitätsbildung mit wichtigen philologischen, historischen und philosophischen Arbeiten auf den Plan traten. Abraham Geiger beanspruchte bereits in jungen Jahren einen Platz in der ersten Reihe dieser neuen Gelehrtengeneration, den er zeitlebens mit intellektueller Brillanz ebenso wie mit großem Selbstbewusstsein zu verteidigen wusste. ${ }^{15}$ Gegen den Begriff „Wissenschaft des Judentums“ brachte Geiger keine grundsätzlichen Einwände vor, doch bevorzugte er im Grunde das Etikett „jüdische Theologie“, um die eigene Forschung schlagwortartig $\mathrm{zu}$ beschreiben. ${ }^{16}$

Nähert man sich Geigers Leitbild einer wissenschaftlichen Theologie in Abgrenzung von anderen Lesarten jüdischer Wissenschaft, dann ist es zunächst hilfreich, dessen zum Teil sachliche, zum Teil aber auch polemische Auseinandersetzung mit dem zeitgenössischen Schrifttum zu beleuchten. Denn Geiger kommentierte die jüdische Literatur seiner Gegenwart mit spitzer Feder, die auch vor Freunden und Vertrauten nicht Halt machte, wenn es galt, sein Plädoyer für ein Forschungsethos auf der Höhe der Zeit zu untermauern. Besonders aufschlussreich ist seine ambivalente Haltung zu Leopold Zunz, dessen kompromissloses Wissenschaftsideal ja ebenfalls schulbildend wirkte und Generationen von Gelehrten als Inspiration diente. Geiger war mit Zunz erstmalig als 20jähriger Student in Kontakt getreten, der sich dann über Jahrzehnte fortsetzen sollte und neben dem brieflichen Austausch auch persönliche Besuche einschloss. Unbeschadet seiner Wertschätzung für Zunz, der ihm ja die Er-

14 Der Begriff „Wissenschaft des Judenthums“ war erstmals im Kreis des 1819 gegründeten Berliner „Vereins für Cultur und Wissenschaft der Juden“ aufgetaucht, der 1822-23 auch die von Leopold Zunz redigierte Zeitschrift für die Wissenschaft des Judenthums herausgab; siehe dazu z. B. Ismar Schorsch, „Breakthrough into the Past: The Verein für Cultur und Wissenschaft der Juden“, in Leo Baeck Institute Year Book 33 (1988): 3-28; Siegfried Ucko, „Geistesgeschichtliche Grundlagen der Wissenschaft des Judentums (Motive des Kulturvereins vom Jahre 1819)“, in Zeitschrift für die Geschichte der Juden in Deutschland 5 (1935): 1-34.

15 Vgl. Wiese, Homolka und Brechenmacher, Hrsg., Jüdische Existenz in der Moderne.

16 Vgl. etwa Abraham Geiger, „Einleitung in das Studium der jüdischen Theologie (1849)“, in Abraham Geiger's Nachgelassene Schriften, hrsg. von Ludwig Geiger, Bd. 2 (Berlin: Gerschel, 1875), 1-32; idem, „Allgemeine Einleitung in die Wissenschaft des Judenthums“, in ibidem, 33-245; vgl. außerdem Ismar Elbogen, Ein Jahrhundert Wissenschaft des Judentums (Berlin: Philo Verlag, 1922), 40 f.; Stallmann, Abraham Geigers Wissenschaftsverständnis; Ismar Elbogen, „Abraham Geiger“, in Jahrbuch für Jüdische Geschichte und Literatur Nr. 14 (1911): 75; Karl Erich Grözinger, Jüdisches Denken. TheologiePhilosophie-Mystik, Bd. 3: Von der Religionskritik der Renaissance zu Orthodoxie und Reform im 19. Jahrhundert (Frankfurt und New York: Campus-Verlag, 2009), 578-616. 
fahrung eines Vierteljahrhunderts voraushatte, betrachtete er dessen umfangreiches Werk bereits früh mit einer kritischen Distanz, die auf den unterschiedlichen Forschungsperspektiven gründete. Seine eigene Forschung schlug eine neue Richtung ein, die Abhilfe versprach gegen jene Unzulänglichkeiten, die Geiger der bisherigen Forschung anlastete. ${ }^{17}$

Im Zentrum der Kritik an Zunz stand dessen dezidiertes Desinteresse an theologischen Inhalten. Was war darunter zu verstehen? Wie Geiger bereits 1836 in einem Privatschreiben an den Mathematiker Moritz Abraham Stern (1807-1894) bemängelte, vertrat Zunz eine Gelehrsamkeit, die der inneren Entwicklung des jüdischen Glaubens zu wenig Aufmerksamkeit schenkte. ${ }^{18}$ Damit zusammen hing auch seine Beobachtung, dass Zunz das jüdische Schrifttum nicht als eine religiöse, sondern als eine Volksliteratur präsentierte. Zunz' Version einer Wissenschaft des Judentums beschränke sich demnach auf eine bloße Altertumswissenschaft, die zwar die Erscheinungen der Zeiten in den Blick rücke, jedoch weder ein Verständnis der Vergangenheit selbst schaffe noch die Frage nach deren Bedeutung in ihrem Bezug zur Gegenwart stelle. Von diesem Blickwinkel aus betrachtet lieferten Zunz und seinesgleichen lediglich akribisch gefertigte Bausteine zu einer Geschichte des Judentums, deren leitende Ideen sie aber außer Acht ließen. ${ }^{19}$

Vehementen Einspruch erhob Geiger vor allem gegen das viel diskutierte Buch Zur Geschichte und Literatur, eine Sammlung von Abhandlungen zur jüdischen Geschichte, Literaturgeschichte und Bibliographie, die Zunz 1845 im Druck vorlegte. In dem radikalen Reformblatt Der Israelit des neunzehnten Jahrhunderts, das der sächsisch-weimarische Landrabbiner Mendel Hess (1807-1871) herausgab, platzierte Geiger eine mehrteilige Besprechung der Veröffentlichung. Wer Geigers Nichteinverständnis mit Zunz' Wissenschaftsideal verstehen will, muss sich auch in Erinnerung rufen, dass Zunz ausdrücklich die Maxime ausgegeben hatte, die jüdische Wissenschaft müsse sich „zunächst von der Theologie emanzipiren und zur geschichtlichen Anschauung erheben“, d.h. von einer religiösen Verwertung der Forschung absehen, die er insbesondere dem Reformjudentum anlastete. ${ }^{20}$ Dass sich Geiger am Schluss dieser Rezension als Zunz’ „treu aufhorchenden und begierig lauschenden Schüler“

17 Geiger, Abraham Geiger, 16f.; Ismar Schorsch, Leopold Zunz: Creativity in Adversity (Philadelphia: University of Pennsylvania Press, 2016), passim; Michael A. Meyer, „Jewish Religious Reform and Wissenschaft des Judentums. The Positions of Zunz, Geiger and Frankel“, in Leo Baeck Institute Year Book 16 (1971): $19-32$.

18 „Abraham Geiger an Leopold Zunz, 31. März 1836“, in Abraham Geiger’s Leben in Briefen, hrsg. von Ludwig Geiger (Berlin: Gerschel, 1878): 90.

19 Abraham Geiger, „Literarisch-kritische Uebersicht“, in Wissenschaftliche Zeitschrift für jüdische Theologie 6 (1847): 95; vgl. auch idem, „Jüdische Zeitschriften“, in Wissenschaftliche Zeitschrift für jüdische Theologie 4 (1839): 288f.; idem, „Einleitung in das Studium der jüdischen Theologie“, 27; idem, „Jüdische Geschichte von 1830 bis zur Gegenwart (Vorlesungen gehalten zu Breslau, Winter 1849/ 50)“, in Abraham Geiger's Nachgelassene Schriften, hrsg. von Geiger, Bd. 2, 261.

20 Dass auch Leopold Zunz eine Forschung betrieb, die von religiösen Interessen geleitet wurde, kann hier nur angedeutet, aber nicht ausführlich erläutert werden; siehe dazu Schorsch, Leopold Zunz. 
bekannte, mochte sich auf dessen philologische Sorgfalt beziehen. Als Anschauungsobjekt diente ihm die von Zunz dargebotene Forschung aber zugleich, um sie als radikales wissenschaftliches Gegenmodell zu entwerten: In ihrer positivistischen Fixierung produzierte sie zwar überprüfbares Wissen, die den Phänomenen der jüdischen Vergangenheit als solchen bereits von vornherein Bedeutung zumaß, ohne die Fakten auch kritisch auf ihre religiöse Gegenwartsrelevanz hin zu befragen. ${ }^{21}$

\section{II}

Es bleibt unklar, warum die Rezension nicht in der Wissenschaftlichen Zeitschrift für jüdische Theologie abgedruckt wurde, die Geiger seit 1835 (,in Verbindung mit einem Vereine jüdischer Gelehrter") herausgab und idealerweise als Forum einer von zeitgenössischen religiösen Erkenntnisinteressen geleiteten Forschung dienen sollte. ${ }^{22}$ Das Periodikum, das - teilweise unregelmäßig - bis 1847 erschien, brachte insbesondere Studien $\mathrm{zu}$ historischen und philosophischen Themenfeldern sowie zeitgenössische Reflexionen. Beiträge zu einer Glaubenslehre des Judentums sind in den insgesamt sechs Jahrgängen allerdings fast gar nicht zu finden. Immerhin gelang es dem Pädagogen Michael Creizenach (1789-1842) sowie dem Orientalisten Joseph Dernburg (Dérenbourg, 1811-1895), mit Geigers Billigung zaghafte Versuche einer systematischen Annäherung an die Grundlehren der jüdischen Religion unterzubringen. ${ }^{23}$ Doch im Allgemeinen ging es in dem Periodikum nicht darum, Aussagen

21 Abraham Geiger „Recension. Zur Geschichte und Literatur. Von Dr. Zunz. Erster Band. Berlin, Veit \& Comp. 1845. VIII u. 607 S. gr. 8., S.“; in Literaturblatt zum Israeliten des neunzehnten Jahrhunderts 1 (1846): 82; vgl. „Geiger an Zunz, 26. Dezember 1845“, in Abraham Geiger's Leben in Briefen, hrsg. von Geiger, 186; Leopold Zunz, ,Zur Geschichte und Literatur“, in idem, Gesammelte Schriften, Bd. 1 (Berlin: Gerschel, 1875): 57; Michael A. Meyer, „Abraham Geiger’s Historical Judaism“, in New Perspectives on Abraham Geiger, hrsg. von Petuchowski, 10 f.; Kerstin von der Krone, Wissenschaft in Öffentlichkeit. Die Wissenschaft des Judentums und ihre Zeitschriften (Berlin u. a.: de Gruyter, 2012), 173, Anm. 33; Ismar Schorsch, „Ideology and History in the Age of Emancipation“, in idem, From Text to Context, 276-278; und vor allem idem, Leopold Zunz, 131-141.

22 Barbara Suchy, „Die jüdischen wissenschaftlichen Zeitschriften in Deutschland von den Anfängen bis zum Ersten Weltkrieg. Ein Überblick“, in Wissenschaft des Judentums, hrsg. von Carlebach, 184-186; von der Krone, Wissenschaft in Öffentlichkeit, 58-61. Möglicherweise fürchtete Geiger, Zunz als Mitarbeiter an der Wissenschaftlichen Zeitschrift für jüdische Theologie zu verlieren. Dieser hatte aber bis dahin ohnehin nur Analekten und kürzere Beiträge geliefert; siehe die Bibliographie des Leopold Zunz Archivs in http://www.jewish-archives.org/nav/classification/11214 (29. Mai 2018); sowie Schorsch, Leopold Zunz, 92-94.

23 Michael Creizenach, „Grundlehren der israelitischen Religion“, in Wissenschaftliche Zeitschrift für jüdische Theologie 1 (1835): 39-51 und 327-339 sowie in Wissenschaftliche Zeitschrift für jüdische Theologie 2 (1836): 68-77 und 436-445; Joseph Dernburg, „Das Wesen des Judenthums nach seinen allgemeinsten Grundzügen“, in Wissenschaftliche Zeitschrift für jüdische Theologie 4 (1839): 12-18; vgl. auch den Brief von A. Geiger an J. Dernburg, vom 10. April 1837, in Ludwig Geiger, Hrsg., „Abraham Geigers Briefe an J. Dérenbourg (1833-1842)“, in Allgemeine Zeitung des Judenthums 60 (1896): 190. 
über Gott oder über jüdische Gotteserfahrungen zu machen. In zahlreichen Aufsätzen unter die Lupe genommen wurden die Religionspraxis und deren Reform („Ueber die synagogische Zulässigkeit und Einrichtung der Confirmation“; „Ueber die Abschaffung bestehender Gebräuche“; „Ueber Trauungen in der Synagoge“; „Ueber die jüdischen Trauergebräuche“; „Ueber die Leviratsehe und die Ceremonie des Schuhausziehens“; „Ueber das Entbehren lederner Schuhe am Versöhnungstage“; „Ueber die jüdischen Fasttage“; „Noch ein Wort über das Haartragen der Frauen“; „Ueber religiöse Trauung“; „Materialien zu einem Commissionsbericht über die Speisegesetze“). Die Stoßrichtung dieser Texte war offensichtlich: „Das Bewußtsein des guten Rechts der Reform“, so Geiger im letzten Jahrgang der Wissenschaftlichen Zeitschrift, „soll nun auch in die Lebensverhältnisse eindringen und den religiösen Boden umpflügen.“24

Wichtige Einblicke in seine Agenda gab Abraham Geiger auch in seiner Einleitung in das Studium der jüdischen Theologie, die Ludwig Geiger postum edierte. Das Buch beruhte auf dem Manuskript einer Vorlesung, die der Vater 1849 in Breslau vor jüdischen Studenten gehalten hatte. Die „Theologie als jüdische“, so stellte dieser hier klar, drehe sich um „die Erkenntnis der religiösen Wahrheiten und des ihnen entsprechenden Lebens nach der Lehre des Judenthums“. ${ }^{25}$ Der Text erlaubt Rückschlüsse, welche Anregungen der Autor Friedrich Schleiermacher (1768-1834) verdankte, der sich ja wie Geiger gegen die Dichotomie von Religion und Wissenschaft ausgesprochen hatte. Die Theologie bezeichnete demnach eine handlungsleitende Disziplin, die ihre funktionale Einheit aus dem Bezug auf das Betätigungsfeld der religiösen Leitung bezog. Wenn Geiger der jüdischen Theologie mit Philosophie, Geschichte und Praxis drei verbundene Gebiete zuwies, übertrug er wiederum Überlegungen des protestantischen Kirchenlehrers, dessen Kurze Darstellung des theologischen Studiums ihm unzweifelhaft vertraut war. ${ }^{26}$

24 Abraham Geiger, „Die religiösen Thaten der Gegenwart im Judenthume“, in Wissenschaftliche Zeitschrift für jüdische Theologie 6 (1847): 1.

25 Geiger, „Einleitung in das Studium der jüdischen Theologie“, 4.

26 Vgl. Friedrich Schleiermacher, Kurze Darstellung des theologischen Studiums zum Behuf einleitender Vorlesungen. Zweite, umgearbeitete Ausgabe (Berlin: Reimer, 1830); Christoph Schwöbel, Art. „Theologie“, in Religion in Geschichte und Gegenwart, hrsg. von Hans Dieter Betz, Bd. 8, 4. Aufl. (Tübingen: Mohr Siebeck, 2008): 265 und 302f.; Zu Geiger und Schleiermacher siehe z.B. Stallmann, Abraham Geigers Wissenschaftsverständnis; Carsten Wilke, „Abraham Geigers Bildungsutopie einer jüdischtheologischen Fakultät“, in Jüdische Existenz in der Moderne, hrsg. von Wiese, Homolka und Brechenmacher, 380; Grözinger, Jüdisches Denken, 589f.; sowie Ulrich Steuer, Schleiermachers Religionsphilosophie in ihrer systematischen und historischen Bedeutung für die jüdische Religionsphilosophie (Köln: Typoskript Dissertation, 1969), 122-131; Vermutungen über den Einfluss Schleiermachers auf Geiger hatte bereits 1843 der preußische Kultusminister Johann Albrecht Friedrich von Eichhorn geäußert, als er in dem Streit um die Berufung Geigers nach Breslau diesem eine Audienz gewährte; vgl. Abraham Geiger's Leben in Briefen, hrsg. von Geiger, 121f.; Emanuel Schreiber, Abraham Geiger als Reformator des Judenthums (Loebau/Westpreußen: Richard Skrzeczek, 1879), 105. 
Den Vorwurf, Schleiermacher auch inhaltlich kopiert und auf diese Weise quasi christliche Ideen auf das Judentum übertragen zu haben, wusste Geiger freilich weit von sich $\mathrm{zu}$ weisen. ${ }^{27}$ Im Zusammenhang mit der zentralen Fragestellung dieses Aufsatzes ist jedenfalls eine Beobachtung frappierend: Während Schleiermacher seine Stellung als wichtigster evangelischer Theologe des 19. Jahrhunderts auch durch eine zweibändige Glaubenslehre des evangelischen Christentums untermauerte, liegt von Geiger eben keine Darstellung der jüdischen Glaubensinhalte in zusammenhängender Form vor. ${ }^{28}$ Auch seine Einleitung sparte dieses Themenfeld komplett aus. ${ }^{29}$

\section{III}

Die private Korrespondenz, deren vertrauliche Diktion ja im Regelfall nicht auf ein öffentliches Publikum zielte, liefert erste Anhaltspunkte über Gründe einer skeptischen Zurückhaltung, mit der sich Geiger über das eigene religiöse Weltbild ausließ. Aus seinen Briefen an den frühen Weggefährten Joseph Dernburg entsteht das Bild eines noch jungen Rabbiners, der seit 1832 in Wiesbaden bereits die Verantwortung für eine eigene Gemeinde trug, der aber im Angesicht einer desorientierenden Moderne den eigenen Glauben erst selbst noch befestigen musste. Kritisierte er 1833 das zeitgenössische Judentum zunächst als abstrakte Religion, der es an erbaulichen Ideen mangele und in der Gott den Menschen zu fern stehe, wusste er sich drei Jahre später mit jenem versöhnt. Enthusiastisch berichtete er, inzwischen ein Judentum gefunden $\mathrm{zu}$ haben, das ihn befriedige,

einen Glauben, dessen Grundlagen das Vertrauen auf einen Weltenlenker und die an uns gestellte Anforderung der Gerechtigkeit und Milde ist, der sich in Werken die diesem Anspruche genügen, ausspricht und mit erhebenden Formen zur Erweckung dieser Gesinnungen umgiebt. ${ }^{30}$

27 Vgl. Abraham Geiger, „Offenes Sendschreiben an Herrn Professor Dr. H.A. Holtzmann“, in idem, Das Judenthum und seine Geschichte von der Zerstörung des zweiten Tempels bis zum Ende des zwölften Jahrhunderts (Breslau: Schletter, 1865): 190 - 193; idem, „Allgemeine Einleitung in die Wissenschaft des Judenthums“, 63.

28 Friedrich Schleiermacher, Der christliche Glaube nach den Grundsätzen der evangelischen Kirche im Zusammenhange dargestellt, 2 Bde., 2. Ausgabe (Berlin: Reimer, 1830/31).

29 Geiger erwähnt allerdings Metaphysik und Ethik als Disziplinen einer Religionsphilosophie, die der jüdische Theologe nicht völlig voraussetzungslos betreiben kann; siehe Geiger, „Einleitung in das Studium der jüdischen Theologie“, $7 \mathrm{f}$.; siehe außerdem Geigers kritische Zeilen zur Schleiermacherrezeption in Jüdische Zeitschrift für Wissenschaft und Leben 7 (1869): 211-215; dort bezieht sich Geiger auch auf Schleiermachers kritisches Verhältnis zum Judentum; siehe dazu auch Matthias Blum, „Ich wäre ein Judenfeind“. Zum Antijudaismus in Friedrich Schleiermachers Theologie und Pädagogik (Köln, Weimar und Wien: Böhlau, 2010).

30 „A. Geiger an J. Dernburg, 23. Februar 1836“, in Geiger, „Abraham Geigers Briefe“, 115; vgl. „A. Geiger an J. Dernburg, 15. Juli 1833“, in ibidem, 91; vgl. Schleiermacher, Der christliche Glaube, § 4. 
Auch in späteren Bekenntnissen, in denen der ethische Monotheismus als Gewissheit aus der Innerlichkeit des Individuums hervorging, machte Schleiermacher seinen Einfluss geltend. Gegenüber Moritz Abraham Stern distanzierte sich Geiger 1843 ausdrücklich von den Ideen des Pantheismus, um stattdessen - in deutlicher Anlehnung an Schleiermachers Deutung der Frömmigkeit als Gefühl der „schlechthinnigen Abhängigkeit“ - zu bekräftigen,

dass ich einen Ueberschuss über die Immanenz statuire, dass ich ein Unbegreifliches über uns anerkenne, dass ich dem Gefühle, das sich zum Abhängigkeitsbewusstsein steigert, sein Recht einräume und nicht verkümmert wissen will, dass ich die Leugnung der Religion als einen Irrthum, als einen gefährlichen Irrthum verwerfe. ${ }^{31}$

Unbeschadet solcher Konfessionen widerstrebte es Geiger aber selbst im Austausch mit engen Vertrauten, ausführlichere Auskünfte über sein Credo zu erteilen. Dass Stern Geiger auch in späteren Jahren hartnäckig über dessen Glauben befragte, illustriert zunächst, dass er in Geigers Schriften keinen hinreichenden Aufschluss über diesen Gegenstand zu finden glaubte. Gegenüber seinem Freund bekannte sich Geiger im Sommer $1858 \mathrm{zu}$ einem Theismus, für den er aber als Privatmeinung nicht öffentlich Partei ergreifen wollte. Stern freilich gab sich mit dieser Antwort noch nicht zufrieden, möglicherweise, weil Geiger es zu vermeiden gewusst hatte, Gott als solchen konkret zu benennen. Ungehalten über Sterns Beharrlichkeit, zögerte Geiger monatelang, bis er endlich doch eine weitere Antwort verfasste, in der er nun auch einem personifizierten Gottesgedanken Platz einräumte:

Es ist die unerquickliche Discussion über Gott, auf der Du beharrst. Ich trage seine Ahnung in mir; mein eigner Geist, dessen volle selbständige, vom Körper unabhängige, wenn auch gegenwärtig mit ihm verbundene Persönlichkeit mir eine gewisse Thatsache innerer Erfahrung ist, bürgt mir für die Existenz eines gleichfalls persönlichen Allgeistes, eines Gottes, der wie es das Bedürfniss, das höchste Bedürfniss des Geistes, liebend überströmt. In dieser Ahnung liegt freilich nicht der volle, mit aller Klarheit umschriebene Gedanke, es liegt eine gewisse, sehr wohlthuende Poesie darin, eine Poesie jedoch, deren beraubt die Welt nicht minder als ich selber gar nüchtern würde. [...] Dass bei solcher vollen Anerkennung eines persönlichen Gottes und seines eingreifenden Waltens, aber als eines Geistes, der die vorigen, auch in unserem Geiste sich offenbarenden Gesetze des Geistes in sich trägt, dass es dabei - sage ich - an einzelnen vermenschlichenden Ausdrücken nicht fehlen wird - zumal in Stimmungen, wo eine tiefere Anregung das Herz durchwühlt und dieses seinen Ausdruck verlangt -, will ich nicht in Abrede stellen; es wird jedoch kaum einer Nachsicht dazu bedürfen, solche Ausdrücke entschuldbar zu finden. Lass uns daher über diese philosophische Discussion hinwegkommen. Soweit ich vordringen kann, thue ich es mit aller Unbefangenheit; über meinen eigenen Geist hinaus und gar über die Wurzel hinaus, aus der er Nahrung zieht, kann ich nicht, da glaube ich es beim freudigen Bewusstsein von dem einen, bei der Verehrung der andern wohl bewenden lassen zu dürfen. ${ }^{32}$

31 „A. Geiger an M.A. Stern, 25. August 1843“, in Abraham Geiger’s Leben in Briefen, hrsg. von Geiger, $167 \mathrm{f} . ;$

32 „A. Geiger an M.A. Stern, 28. Dezember 1858“, in Abraham Geiger’s Leben in Briefen, hrsg. von Geiger, 229f.; auch in Geiger, Abraham Geiger, 226; Vogelstein, Systematische Theologie, 248f.; vgl. auch 
Geigers Widerstreben, detaillierte Angaben über die persönliche religiöse Weltanschauung zu machen, hing folglich weniger mit eigenen Zweifeln zusammen, sondern gründete auf der Einsicht des Unvermögens, Glaubensüberzeugungen als überprüfbare Gewissheiten zu präsentieren. Hier spielte auch eine Rolle, dass Geiger in der Erkenntnis der religiösen Wahrheiten des Judentums als positive Religion nicht eine „Aufgabe des Denkens, der philosophischen Betrachtung“ erkennen wollte, sondern sie der Historiographie zuwies, also vornehmlich empirisch aus der Rekonstruktion der Vergangenheit ermitteln zu können glaubte. ${ }^{33}$ Als Schriftsteller und Rabbiner sah sich Geiger aber zugleich vor die Aufgabe gestellt, geistliche Orientierung in einer Epoche zu ermöglichen, die eben auch durch eine Vervielfältigung jüdischer religiöser Selbstpositionierungen bestimmt war. Seine Schriften sowohl zur theoretischen als auch zur praktischen Theologie spiegeln dieses Dilemma wider.

\section{IV}

Geigers Theologie fußte auf einem romantischen Begriff der Religion, der diese nicht objektiv, also als ein gegebenes System von Wahrheiten, sondern subjektiv, vom Individuum her erklärte. Als anthropologische Konstante bezeichnete Religion ein sowohl ubiquitäres als auch unvergängliches Phänomen. Dem Menschen eigen war demnach eine Doppelnatur, die das Bewusstsein einer höheren Weltordnung und das enthusiastische Streben zur sittlichen Selbstvervollkommnung mit der demütigen Einsicht der eigenen Unvollkommenheit verknüpfte. Das universale Sehnen des Menschen nach dem Unendlichen trotz der Unfähigkeit, das Endliche und Begrenzte zu überwinden, galt Geiger zugleich als Bürgschaft für die Wirklichkeit dieses Strebens, das in den verschiedenen Religionen zugleich unterschiedliche Formen annahm. ${ }^{34}$ So wurde der Gottesbeweis quasi aus der Geschichte abgeleitet. Auf die jüdische Religion schauend, bemerkte er:

\footnotetext{
„A. Geiger an M.A. Stern 9. August 1858“, in Abraham Geiger’s Leben in Briefen, hrsg. von Geiger, 227 f.; siehe außerdem Arnulf von Scheliha, „Schleiermachers Deutung von Judentum und Christentum in der fünften Rede ,Über die Religion“ und ihre Rezeption bei Abraham Geiger“, in Christentum und Judentum. Akten des Internationalen Kongresses der Schleiermacher-Gesellschaft in Halle, März 2009, hrsg. von Roderich Barth, Ulrich Barth, Claus-Dieter Osthövener (Berlin und Boston: De Gruyter, 2009): 223. 33 Geiger, „Einleitung in das Studium der jüdischen Theologie“, 4.

34 Abraham Geiger, Das Judentum und seine Geschichte. In vierunddreißig Vorlesungen (Breslau: Jacobsohn, 1910), 9-11; vgl. idem, „Der Mangel an Glaubensinnigkeit in der jetzigen Judenheit. Bedenken eines Laien (1835)“, in Abraham Geiger’s Nachgelassene Schriften, hrsg. von Geiger, Bd. 1, 457; Abraham Geiger, „Abhandlungen aus den Programmen der jüdischen Religionsunterrichtsanstalt in Breslau 1844-1863“, in ibidem, 349; siehe auch Karl E. Grözinger, „Abraham Geigers theologische Wende vor dem Hintergrund der neuzeitlichen Debatte um Religion und Vernunft“, in Jüdische Existenz in der Moderne, hrsg. von Wiese, Homolka und Brechenmacher, 32f.
} 
Das Judenthum wird eine [...] kritische Prüfung auch nicht zu scheuen haben, denn wenn wir auch nicht den Schleiermacher'schen Grundsatz in seiner vollen Ausdrucksweise annehmen können, dass eine vorhandene einflussreiche Stiftung für die Dignität des Stifters oder gar für den unmittelbaren göttlichen Ursprung zeugt, so müssen wir doch eingestehen, dass die Thatsache einer weltgeschichtlichen Institution, die ihren Einfluss gebieterisch ausübt, die Bürgschaft gibt für die Macht des Gedankens, der in ihr waltet, für die Wahrheit der Idee, die sie trägt und Geschichte und Sage erzeugt hat. ${ }^{35}$

Die Pluralisierung der religiösen Ideologien im deutschen Judentum des 19. Jahrhunderts lässt sich nicht zuletzt auch als Konsequenz der Suche nach zeitgemäßen Ausdrucksformen gelebter Frömmigkeit sowohl im Kultus als auch im Alltagsleben der Gläubigen beschreiben. Die Vielfalt im Glauben gründete aber auch auf unterschiedlichen Auslegungen von Offenbarung und Tradition als konstituierenden Faktoren des Judentums. Abraham Geiger hatte bereits 1835, im ersten Jahrgang seiner Wissenschaftliche Zeitschrift für jüdische Theologie, angemahnt, dass die jüdische Literatur sich dringend diesen Hauptfragen zuwenden müsse, um sie sowohl historisch als auch philosophisch zu erörtern. Geigers Theologie ist denn auch ohne seine eigene Deutung des Offenbarungsgeschehens gar nicht zu verstehen. Dabei sollte es ihm gelingen, das Judentum als positive Religion zu präsentieren, in der das allgemeinmenschliche „Ahnen“ einer höheren Macht in einen spezifischen religionshistorischen Kontext gestellt wurde, ohne sich jedoch auf ein konkretes Bild von Gottes eingreifendem Walten $\mathrm{zu}$ beziehen. ${ }^{36}$

Geiger konnte und wollte keine voraussetzungslose jüdische Wissenschaft betreiben, die ja die Religion sowohl zum ausschließlichen Gegenstand der Forschung machte als auch eine religiöse Agenda zur Gestaltung der Gegenwart und Zukunft verfolgte. Der Offenbarungsglaube, den er als conditio sine qua non der theologischen Forschung formulierte, unterschied sich freilich signifikant von traditionellen Auslegungen, indem er das Offenbarungsgeschehen weniger als göttliche Intervention, herablassende Zuwendung, und Übergabe von Weisungen und Belehrungen schilderte, die mit einer sinnlichen Wahrnehmung der Empfänger einhergingen, sondern es als einen inneren Vorgang plötzlicher Einsicht ewiger Wahrheiten beschrieb, die also letztlich vom Menschen selbst ausging. ${ }^{37}$ Die besondere weltgeschichtliche

35 Abraham Geiger, „Allgemeine Einleitung in die Wissenschaft des Judenthums“, 62.

36 Abraham Geiger, „Heuchelei, die erste Anforderung an den jungen Rabbiner unserer Zeit“, in Wissenschaftliche Zeitschrift für jüdische Theologie 1 (1835): 299; vgl. Nathan Rotenstreich, Tradition and Reality: The Impact of History on Modern Jewish Thought (New York: Random House, 1972), 7-18; Gershom Scholem, Über einige Grundbegriffe des Judentums (Frankfurt am Main: Suhrkamp 1970), 90 105; Michael A. Meyer, „Ob Schrift? Ob Geist?-Die Offenbarungsfrage im deutschen Judentum des neunzehnten Jahrhunderts“, in Offenbarung im jüdischen und christlichen Glaubensverständnis, hrsg. von Jacob J. Petuchowski und Walter Strolz (Freiburg, Basel und Wien: Herder, 1981): 175-179; Grözinger, Jüdisches Denken, Bd. 3, 593-604.

37 Allerdings deutete Geiger mehrfach an, dass sein Offenbarungsglaube partiell an die jüdische Philosophie des Mittelalters anknüpfe, also etwa bei Jehuda Halevi und Moses ben Maimon; vgl. Geiger, Das Judentum und seine Geschichte, 37 und 319f. 
Stellung des Judentums hing nun mit dem religiösen Genie der Juden zusammen, denen als Volk die besondere Befähigung eigen war, neue intellektuelle Anschauungen im Sinne einer Offenbarung zu gewinnen. Bezeichnete dieses Genie zunächst eine kollektive geistige Anlage in Form einer besonderen Empfänglichkeit, so blieben der Gesamtheit dennoch konkrete Offenbarungserfahrungen verwehrt. Individuelle Träger und Verkünder der „höheren Erleuchtung“ waren vielmehr die Propheten, deren geläutertes religiöses Bewusstsein mit einer klareren sittlichen Anschauung einherging und sich, verdichtet zur Lehre des Judentums, allmählich im Volk Geltung verschaffte. ${ }^{38}$

Wusste Geiger bereits die Offenbarung als dynamisches menschlich-geistiges Schöpfungswerk, wenngleich göttlicher Abstammung, auch in einen geschichtlichen Bezugsrahmen zu stellen, so endete diese formative Epoche mit der Rückkehr der Juden aus dem babylonischen Exil. Der in der Offenbarung sich ausprägende Geist sei aber, so Geiger, in veränderter Form auch in der Tradition weiter wirksam. Analog zur Natur, wo die gestaltende Kraft Gottes nach Vollendung des Schöpfungswerks sowohl erhaltend als auch als Evolution nachwirke, entfalte sich im Geistesleben die Tradition ebenfalls als Kraft der Entwicklung. Als Ausfluss des göttlichen Geistes wirke sie in der Gesamtheit, erwähle sich aber wiederum besondere Träger, die das Judentum in ihre jeweilige Gegenwart übersetzten und auf diese Weise dessen Lebensfähigkeit bewahrten. Nach Geigerscher Lesart war die jüdische Wissenschaft der Gegenwart nicht nur vor die Aufgabe gestellt, in der Überlieferung die religiöse Wahrheit in ihrer jeweils historischen Fassung und Entwicklung zu erkennen, sondern aus diesem Wissen und der Erkenntnis der Gegenwart auch Konsequenzen für die Fortbildung des Judentums zu ziehen. Als Fortsetzung der Tradition erhielt die wissenschaftliche Theologie damit eine zusätzliche religiöse Aufladung. ${ }^{39}$

\section{V}

Signifikant für Geigers Theologie war deren konfrontativer Gestus, der aus dem Widerspruch erwuchs und diesen sowohl ausdrücklich als auch implizit formulierte. In der Auseinandersetzung mit der Altertumswissenschaft und protestantischen Theo-

\footnotetext{
38 Wie genau nun sich diese „Berührung der menschlichen Vernunft mit dem tiefen Urgrund aller Dinge“ vollzogen hatte, wusste auch Geiger nicht völlig konsistent zu erklären; siehe Geiger, „Einleitung in das Studium der jüdischen Theologie“, 6; idem, „Literaturbriefe aus dem Jahre 1853“, in Abraham Geiger's Nachgelassene Schriften, hrsg. von Geiger, Bd. 2, 331; idem, Das Judentum und seine Geschichte, 36 - 38; vgl. Harvey Hill, „The Science of Reform: Abraham Geiger and the Wissenschaft des Judentum (sic)“, in Modern Judaism 27.3 (2007): 332; Vogelstein, Systematische Theologie, 251-253. 39 Abraham Geiger, „Der Boden zur Aussaat“, in Jüdische Zeitschrift für Wissenschaft und Leben 1 (1862): 6 f.; idem, „Nothwendigkeit und Maass einer Reform des jüdischen Gottesdienstes. Ein Wort zur Verständigung“, in Abraham Geiger’s Nachgelassene Schriften, hrsg. von Geiger, Bd. 1, 203; idem, Das Judentum und seine Geschichte, $75 \mathrm{f}$.
} 
logie konzipierte er seine religionshistorischen Forschungen als counter history, die er dazu benutzte, um die Deutungshoheit über wichtige Kapitel der jüdischen Vergangenheit zurückzugewinnen..$^{40}$ Seine wissenschaftliche Arbeit richtete sich aber noch mehr gegen den Hegemonialanspruch konservativer Strömungen des zeitgenössischen Judentums, deren theologische Gewissheiten er mit der und durch die Geschichte zu erschüttern suchte. Im Zentrum dieser teilweise auch polemisch ausgefochtenen Konflikte stand die Widerlegung des sakralen Statusanspruchs zentraler jüdischer Texte. An Dernburg schrieb Geiger im November 1836 die kämpferischen Zeilen:

Der Talmud muß weg, die Bibel, jener Komplex von meistens so schönen und erhabenen, vielleicht den erhabendsten menschlichen Büchern, muß als Göttliches weg. [...] Um Himmelswillen, wie kann diese Lügenhaftigkeit fortdauern, immer und ewig auf den Kanzeln die Geschichten der Bibel als wahre Begebenheiten zu erklären, und an sie als an die höchsten Weltereignisse, an sie, die wir für uns in das Reich der Sage versetzt haben, Lehren anzuknüpfen und, wenn auch weiter gar nichts, Texte aus ihr zu entlehnen? Wie lange noch soll jene Verdrehung des kindlichen Geistes mit jenen Geschichten, die den natürlichen Sinn des zarten Menschenkindes entstellen, fortdauern? Wie dies wohl zu ändern? Je nun, eben durch das Hintreiben in die Enge, so daß es nicht mehr stattfinden kann, dadurch, daß man sich und anderen diesen Widerspruch aufdeckt, dadurch, daß man in alle Schlupfwinkel den Ausflüchte Suchenden verfolgt und so endlich den großartigen Einsturz mit bewirkt, der eine alte Welt unter seinen Trümmern begräbt, und eine neue uns öffnet. ${ }^{41}$

Die supranaturalistische Auffassung, dass es sich bei der schriftlichen und mündlichen Tora um Zeugnisse einer göttlichen Offenbarung ohne Verfallsdatum handelte, konnte in einer Theologie, die das Entwicklungsprinzip zur obersten Maxime erhob, keinen Platz haben. Die hebräische Bibel bezeichnete also die „Schriften der heiligen Gemeinschaft, der Heiligkeit oder des Heiligthums“, aber eben keine heiligen Schriften. Geiger wollte Texte mit regulativem Anspruch durchaus als Urkunden anerkennen, die für den Geist des Judentums in der Zeit ihrer Entstehung und Bearbeitung zeugten. Aufgabe der Theologie sei es freilich, anknüpfend an die Erkenntnis eines ewigen Gehalts des Judentums, dessen Ausprägung sich im Zeitenlauf verän-

40 Susannah Heschel, Der jüdische Jesus und das Christentum. Abraham Geigers Herausforderung an die christliche Theologie (Berlin: Jüdische Verl.-Anst., 2001), 25-54; Amos Funkenstein, Jüdische Geschichte und ihre Deutungen (Frankfurt am Main: Jüdischer Verlag, 1995), $38 \mathrm{f}$.

41 „Geiger an Dernburg, 8. November 1836“, in „Abraham Geigers Briefe“, 165; vgl. auch „Geiger an Jakob Auerbach, 13. Januar 1846“, in Abraham Geiger's Leben in Briefen, hrsg. von Geiger, 188; erste Zweifel am orthodoxen Glauben, so wusste sich Geiger in seinem Tagebuch zu erinnern, waren ihm im Alter von elf Jahren gekommen, ausgelöst durch die Lektüre von Beckers Handbuch der Weltgeschichte; vgl. Geiger, Hrsg., Abraham Geiger's Leben in Briefen, 7; siehe auch Michael A. Meyer, „Abraham Geiger-Der Mensch“, in Jüdische Existenz in der Moderne, hrsg. von Wiese, Homolka und Brechenmacher, 5 .

Es ist viel über den Einfluss von David Friedrich Strauss' und der Tübinger Schule auf Geiger geschrieben worden; siehe dazu Heschel, Der jüdische Jesus, 184-189; Meyer, Antwort auf die Moderne, $142 \mathrm{f}$. 
dere, das religiöse Bewusstsein der Gegenwart zur Geltung zu bringen, „den religiösen Wahrheiten ihren Ausdruck zu geben, wie er der Zeit angemessen ist. “42 Hinzu trat die Erkenntnis, dass auch die Bücher der Bibel selbst in der vorliegenden hebräischen Fassung sowie in den Übersetzungen als das Ergebnis eines Tradierungsprozesses betrachtet werden müssen, in dem sich die inneren Wandlungen des Judentums in der Epoche seit der Rückkehr aus dem babylonischen Exil bis zum Abschluss des Talmud widerspiegelten. Sein Hauptwerk Urschrift, das Geiger 1857 herausbrachte, widmete sich dieser Überlieferungsgeschichte, die dem Glauben des gesetzestreuen Judentums an einen göttlichen Ursprung des masoretischen Textes also eine doppelte Absage erteilte, ohne aber damit auch dessen Bedeutung als Urkunde abzustreiten, in der sich die religiösen Lehren und Wahrheiten des Judentums als ethischer Monotheismus abbildeten. ${ }^{43}$

Welche Verachtung er für den „niedrigste[n] Standpunkt der Unmittelbarkeit“ empfand, ließ Geiger auch in scharfen Besprechungen, so etwa in der Auseinandersetzung mit dem Vordenker der Neo-Orthodoxie Samson Raphael Hirsch (18081888), durchblicken. ${ }^{44}$ Auch gegen die „Hirnlosigkeit“ der Annahme, dass die mündliche Lehre unmittelbare Tradition sei, ${ }^{45}$ schrieb Geiger in seiner Urschrift an, indem er das jüdische Sakralrecht aus jeglichem Offenbarungszusammenhang im Sinne einer göttlichen Inspiration herauslöste und ihm stattdessen einen Evolutionsprozess zumaß, den er im Wesentlichen aus dem Konflikt zwischen Pharisäern und Sadduzäern herleitete. Mit dem Abschluss des Talmud sei das Judentum dann in eine Epoche der „starren Gesetzlichkeit“ eingetreten, in der das noch für die Offenbarung und Tradition gültige Entwicklungsprinzip ausgehebelt worden sei. Erst in der Gegenwart verschaffe sich mit der Kritik ein neues Zeitalter Geltung. Um das Judentum aus seiner vierzehn Jahrhunderte dauernden Umklammerung durch den Talmud zu befreien, gelte es nun, diesen nicht mehr als göttlichen Befehlskatalog von unbefristeter Validität $\mathrm{zu}$ betrachten, sondern als religionshistorisches Dokument menschlichen Ursprungs:

\footnotetext{
42 Vgl. Geiger, „Einleitung in das Studium der jüdischen Theologie“, passim; idem, „Einleitung in die biblischen Schriften“, in Abraham Geiger's Nachgelassene Schriften, hrsg. von Geiger, Bd. 4, 12; idem, „Jüdische Geschichte von 1830“, 266.

43 Abraham Geiger, Urschrift und Uebersetzungen der Bibel in ihrer Abhängigkeit von der innern Entwicklung des Judenthums (Breslau: Hainauer, 1857); vgl. idem, „Einleitung in die biblischen Schriften“, 132.

44 Abraham Geiger, „Recensionen“, in Wissenschaftliche Zeitschrift für jüdische Theologie 4 (1839): 355-381, idem, „Das Verhältniß des natürlichen Schriftsinnes zur thalmudischen Schriftdeutung. Eine Skizze“, in Wissenschaftliche Zeitschrift für jüdische Theologie 4 (1839): 53f.; zu Hirsch siehe z. B. Roland Tasch, Samson Raphael Hirsch. Jüdische Erfahrungswelten im historischen Kontext (Berlin: De Gruyter, 2010).

45 Vgl. Abraham Geiger, „Die letzten zwei Jahre. Sendschreiben an einen befreundeten Rabbiner (1840)“, in Abraham Geiger’s Nachgelassene Schriften, hrsg. von Geiger, Bd. 1, 31.
} 
Das Thalmudstudium muss von nun an, wenn es den Anspruch auf Wissenschaftlichkeit erheben will, sich ganz anders mit den Quellen befassen als bisher, es muss die arg hintangesetzten Werke zu Ehren bringen und die hoch überschätzte babylonische Gemara auf die Stufe versetzen, die ihr gebührt als dem jüngsten nach bestimmten Voraussetzungen umgewandelten Producte, als einem neuen Werke, das mit Unrecht den Anspruch erhebt, der treue Mund des grauesten Alterthums zu sein. [...] Die Erstarrung, der Tod eines jeden wahren religiösen Lebens, sich stützend auf die angebliche Abgeschlossenheit, welche einmüthig bezeugt werde, muss der Erkenntniss der geschichtlichen Bewegung weichen. ${ }^{46}$

Wer die religiösen Auseinandersetzungen im deutschen Judentum im 19. Jahrhundert unter die Lupe nimmt, wird feststellen können, dass mit den unterschiedlichen Vorstellungen zeitgemäßer religiöser Lebensführung auch eine Konfessionalisierung einherging, die sich allerdings nicht als intrakonfessionelle Konsolidierung mit Tendenzen der Uniformierung, Klerikalisierung, Zentralisierung und Sozialreglementierung gestaltete. Konfessionalisierung im jüdischen Kontext beschrieb im Gegenteil eine innere Pluralisierung, d.h. die Entstehung von religiösen Bekenntnissen, deren Exklusivität sich an signifikanten theologischen Unterscheidungsmerkmalen festmachte. ${ }^{47}$ Die zunehmende Vielfalt des jüdischen Glaubens befeuerte zudem eine Diskussion über die Existenz verbindlicher Glaubenslehren, in die auch Geiger eingriff, um seinem historisch-kritischen Standpunkt Gehör zu verschaffen. ${ }^{48}$ Dass er sich so dezidiert gegen die Existenz jüdischer Dogmen aussprach, mag zum einen mit der apologetisch-polemischen Bemühung zusammenhängen, die Eigenheit und Vorzüge des Reformjudentums auch an grundsätzlichen Unterschieden zum christlichen Glauben festzumachen, in dem die Dogmatik ihren festen Platz in der Theologie be-

46 A. Geiger, Urschrift, IIIf.; vgl. idem, „Allgemeine Einleitung in die Wissenschaft des Judenthums“, 127 et passim; siehe auch Ismar Schorsch, „Scholarship in the Service of Reform“, in idem, From Text to Context, 318f.

47 Zur Konfessionalisierung im Judentum vgl. Olaf Blaschke, „Bürgertum und Bürgerlichkeit im Spannungsfeld des neuen Konfessionalismus von den 1830er Jahren bis zu den 1930er Jahren“, in Juden, Bürger, Deutsche. Zur Geschichte von Vielfalt und Differenz 1800-1933, hrsg. von Andreas Gotzmann, Rainer Liedtke und Till van Rahden (Tübingen: Mohr Siebeck, 2001): 33-66; Jacob Toury, „Die Revolution von 1848 als innerjüdischer Wendepunkt“, in Das Judentum in der deutschen Umwelt 1800 -1850, hrsg. von Hans Liebeschütz und Arnold Paucker (Tübingen: Mohr, 1977): 373; David Sorkin, „Religious Reforms and Secular Trends in German-Jewish Life. An Agenda for Research“, in Leo Baeck Institute Year Book 40 (1995): 174.

48 Vgl. Schoeps, Jüdischer Glaube in dieser Zeit, 33; von der Krone, Wissenschaft in Öffentlichkeit, 427429; dies., „Jüdische Wissenschaft und modernes Judentum: Eine Dogmendebatte“, in Die „Wissenschaft des Judentums“, hrsg. von Meyer und Kilcher, 119f.; siehe außerdem Leopold Löw, Jüdische Dogmen. Offenes Sendschreiben an den Herrn Dr. Ignatz Hirschler, Eigenthümer des „Izraelita Közlöny“ (Pest: Aigner, 1871). 
hauptete. ${ }^{49}$ Zieht man seine Anstrengungen zur Dekonstruktion grundlegender Überzeugungen der Orthodoxie in Betracht, dann lässt sich Geigers Position aber zugleich in seinem innerjüdischen Bezugsrahmen einordnen. Geiger suchte seine progressive Theologie auch in Abgrenzung von anderen, konservativeren Strömungen zu definieren, denen er einen „unjüdischen“ Dogmatismus nachweisen zu können glaubte.

Anlass zu einer klärenden Positionsbestimmung bot eine Kontroverse mit Manuel Joël (1826-1890), der 1864 als Breslauer Gemeinderabbiner Abraham Geiger ersetzt hatte, nachdem dieser einem Ruf nach Frankfurt am Main gefolgt war. Joël lebte bereits seit 1854 in Breslau, wo er vor seiner Wahl zum Rabbiner als Dozent am JüdischTheologischen Seminar unterrichtet hatte - einem Rabbinerseminar, das unter der Leitung Zacharias Frankels (1801-1875) für eine moderate Modernisierung des Judentums eintrat. ${ }^{50}$ Von dem Wunsch, einen Ausgleich zwischen reformkritischen und progressiven Positionen zu erzielen, zeugten vor allem Joëls Eingriffe in die Liturgie der Gemeinde. 1872 erschien seine tendenziell konservativere Revision jenes Siddurs, den Geiger 1854 mit deutlicher Reformabsicht publiziert hatte.

An Hinweisen, wie sehr Geiger mit der Überarbeitung haderte, mangelt es nicht. Bereits 1869 hatte er ein liturgisches Manifest Joëls zum Gegenstand einer scharfzüngigen Abrechnung gemacht. ${ }^{51}$ Seine Einlassungen gegen Joël liefern auch weitere Hinweise zu Geigers Skepsis gegenüber einer systematischen Theologie des Judentums. In seiner Broschüre Zur Orientirung in der Cultusfrage hatte Joël die Auffassung vertreten, dass das Judentum durchaus über Dogmen im Sinne von normativen Glaubensvorstellungen verfüge, zu denen sich auch der freisinnige Theologe a priori bekennen müsse, weil ihm andernfalls die innere Berufung für sein Amt fehle. Geiger glaubte, in der Festlegung eines verpflichtenden Glaubensbestandes vor allem das Bemühen der Orthodoxie sowie der „Vermittlungstheologie“ erkennen zu können, ihre progressiven Gegner zu delegitimieren und auszugrenzen. Für das Judentum re-

49 Vgl. Geiger, „Die letzten zwei Jahre“, 27; idem, „Das Verhalten der Kirche gegen das Judenthum in der neueren Zeit“, in idem, Das Judenthum und seine Geschichte. Dritte Abtheilung: Vom Anfange des dreizehnten bis zum Ende des sechszehnten Jahrhunderts (Breslau: Schletter, 1871), 172.

50 Zu Manuel Joël vgl. Caesar Seligmann, „Rabbiner Dr. Manuel Joël zu seinem hundertjährigen Geburtstage 19. Oktober 1926. Sein Leben und seine Persönlichkeit“, in Monatsschrift für Geschichte und Wissenschaft des Judentums 70 (1926): 305-315; Michael A. Meyer, „The Career of a Mediator. Manuel Joël, Conservative Liberal“, in Transversal 14.2 (2016): 56 - 64. Zum Seminar vgl. Andreas Brämer, „Die Anfangsjahre des Jüdisch-Theologischen Seminars-Zum Wandel des Rabbinerberufs im 19. Jahrhundert“, in In Breslau zu Hause? Juden in einer mitteleuropäischen Metropole der Neuzeit, hrsg. von Manfred Hettling, Andreas Reinke und Norbert Conrads (Hamburg: Dölling und Galitz, 2003): 99-112. 51 Manuel Joël, Zur Orientirung in der Cultusfrage (Breslau: Schletter'sche Buchhandlung, 1869); Abraham Geiger, Etwas über Glauben und Beten. Zu Schutz und Trutz (Breslau: Schletter'sche Buchhandlung, 1869); vgl. Max Freudenthal, „Manuel Joël und die Kultusfrage“, in Monatsschrift für Geschichte und Wissenschaft des Judentums 70 (1926): 330 -347; David Ellenson, „The Israelitische Gebetbücher of Abraham Geiger and Manuel Joël“, in Leo Baeck Institute Year Book 44 (1999): 143-164. 
klamierte er eine Freiheit, in der sowohl das Wissen um die geschichtliche Entwicklung als auch das persönliche Bewusstsein zur Geltung kam. ${ }^{52}$

Dass Geiger seinem Breslauer Nachfolger so vehement widersprach, überrascht allerdings insofern, als Joël durchaus keinen radikalen Gegenstandpunkt vertrat, sondern ebenfalls eine historisierende Anschauung präsentierte, in die er auch die Dogmen einbezog. Diese erfuhren nämlich, so Joël, zu keinem Zeitpunkt eine endgültige Fixierung, sondern seien in der Vergangenheit Gegenstand unterschiedlicher und sich verändernder Auslegungen gewesen, deren Schranken indes vom religiösen Schriftenkanon gesetzt wurden. Geiger war von dieser Position gar nicht so weit entfernt: Bereits in den 1840er Jahren hatte er die Ansicht verkündet, dass das Judentum zwar keine unveränderlichen Dogmen enthalte, deren Anerkennung Voraussetzung der Zugehörigkeit zur Glaubensgemeinschaft sei, dass es aber durchaus über einen Bestand von wesenhaften Grundsätzen verfüge, aus denen sich der Maßstab des jüdischen Handelns ableite. Jeder Gläubige stehe in der Pflicht, solche grundlegenden Wahrheiten des jüdischen Glaubens in sich zu befestigen, ,und diese Wahrheiten gestalten sich ihm natürlich zu Grund- und Glaubenssätzen. “53

Wie zu zahlreichen anderen Gelegenheiten präsentierte Geiger auch in der Auseinandersetzung mit Joël das Konzept der „religiösen Idee“, die er dem Dogmenbegriff entgegenstellte. Gegen den Aufklärungsphilosophen Moses Mendelssohn (17291786), der ja das Judentum als offenbartes Religionsgesetz charakterisiert hatte, das die Wahrheiten der Vernunftreligion lediglich voraussetze, aber nicht enthalte, argumentierte Geiger, dass das positive Judentum mit neuen religiösen Ideen in die Geschichte eingetreten sei. Im Kern überzeitlich und unwandelbar, manifestierten sich diese Ideen aber im geschichtlichen Verlauf in unterschiedlicher Form und Gestalt. Geiger postulierte eine wissenschaftliche Theologie ohne Denkverbote, die ihm auch als Voraussetzung galt, um die religiösen Ideen im Judentum in noch reinerer Form zur Geltung zu bringen. Der religiöse Fortschritt, der sich insbesondere gegen den hegemonialen Anspruch des Religionsgesetzes richtete, beschrieb somit auch eine fortwährende und niemals abgeschlossene Annäherung der subjektiven Wahrheit an eine objektive Wahrheit, die aber letztendlich keine ausschließlich jüdischen Adressaten hatte, sondern universale Geltung beanspruchte. ${ }^{54}$

52 Geiger, Etwas über Glauben und Beten, 25 und 29 et passim.

53 Geiger, „Abhandlungen aus den Programmen der jüdischen Religionsunterrichtsanstalt“, 322f.; vgl. idem, Etwas über Glauben und Beten, 2-10; Joël, Zur Orientirung in der Cultusfrage, 10 - 12; siehe auch idem, Zum Schutz gegen „Trutz“. Eine nothgedrungene Ergänzung der Schrift: „Zur Orientirung in der Cultusfrage“ (Breslau: Schletter, 1869); sowie Ken Koltun-Fromm, Abraham Geiger's Liberal Judaism. Personal Meaning and Religious Authority (Bloomington und Indianapolis: Indiana Univ. Press, 2006), $122 \mathrm{f}$.

54 Geiger, Etwas über Glauben und Beten, 8 und 10 et passim; vgl. auch idem, „Die zwei verschiedenen Betrachtungsweisen. Der Schriftsteller und der Rabbiner“, in Wissenschaftliche Zeitschrift für jüdische Theologie 4 (1839): 321-333; idem, „Jüdische Zeitschriften“, in Wissenschaftliche Zeitschrift für jüdische Theologie 5 (1844): 374f. Zu Moses Mendelssohn vgl. z. B. Julius Guttmann, Die Philosophie des Ju- 
Geigers vehemente Opposition gegen Joël hing wesentlich mit der zentralen Bedeutung des synagogalen Kultus zusammen, die er auch in Darlegungen zur Gebetbuchreform hervorhob. Anders als bei allen übrigen religiösen Handlungen, die er als Ausdruck einer individuellen Überzeugung in die Selbstverantwortung des Gläubigen stellte, wollte Geiger das gemeinschaftliche Gebet als kollektives Glaubensbekenntnis in den Mittelpunkt der Frömmigkeitspraxis platziert wissen, dem die Reform ihr besonderes Augenmerk zu widmen habe. Dabei ging es weniger um die Einhaltung eines Gebots, die Erfüllung einer Pflicht gegenüber Gott, sondern vielmehr darum, den religiösen Gefühlen und Bedürfnissen der Betenden ein Ventil zu verschaffen. Bei der Umgestaltung des Gottesdienstes, der als reinste Ausprägung des Gesamtbewusstseins den religiösen und ästhetischen Zeitgeist zum Ausdruck bringen sollte, sah sich Geiger aber mit bedeutenden Hindernissen konfrontiert. Hier kam wiederum zum Tragen, dass sich die Anschauungen des Glaubens als bloße Ahnungen einer exakten intellektuellen Erkenntnis entzogen. In einer Zeit, in der sich der Wunsch zur Umgestaltung der Liturgie langsam Bahn brach, aber noch auch auf bedeutenden Widerstand stieß, war die Suche nach einer Gebetsordnung, die formal und inhaltlich die Zustimmung der Gesamtheit der Gläubigen fand, ohnehin eine Illusion. Diese Erfahrung hatte Geiger bereits als Rabbiner in Breslau machen müssen. ${ }^{55}$

Seinen Widerspruch gegen Joëls Bekenntnis zum Dogma untermauerte Geiger vor allem mit Hinweisen auf solche Glaubensüberzeugungen, die zwar in der Geschichte des Judentums einst einen wichtigen Platz eingenommen hatten, aber im Zeitalter der Verbürgerlichung bei den Gläubigen keine Andacht mehr erzeugten. Zeigte sich Geiger in Fragen der Gebetsprache sowie der Gottesdienstdauer vermittlungsbereit, lehnte er in Angelegenheiten des Gebetsinhalts Kompromisse kategorisch ab. Der Reform wies er die Aufgabe zu, überholte religiöse Vorstellungen aus den Gebetstexten zu streichen, bzw. Formulierungen zu finden, die nicht im Widerspruch zu einer geläuterten Auffassung standen. Überlieferten Auffassungen, die in religiöser oder ästhetischer Hinsicht Empörung auslösten, wollte Geiger im Gebetdienst keinen Platz mehr eingeräumt wissen. ${ }^{56}$

\footnotetext{
dentums (München: Reinhardt, 1933), 312; vgl. auch Max Wiener, Jüdische Religion im Zeitalter der Emanzipation (Berlin: Philo Verlag, 1933), 175-257.

55 Abraham Geiger, Unser Gottesdienst. Eine Frage, die dringend Lösung verlangt (Breslau: Schletter, 1868), 1-3; idem, Das Judentum und seine Geschichte, 176; vgl. auch idem, Grundzüge und Plan zu einem neuen Gebetbuche (Breslau: Leopold Freund, 1849). Zu Geiger in Breslau siehe z. B. Andreas Brämer, „Ist Breslau „in vielfacher Beziehung Vorort und Muster für Schlesien“? Religiöse Entwicklungen in den jüdischen Gemeinden einer preußischen Provinz im 19. Jahrhundert“, in Jüdisches Leben zwischen Ost und West. Neue Beiträge zur jüdischen Geschichte in Schlesien, hrsg. von Andreas Brämer, Arno Herzig und Krzysztof Ruchniewicz (Göttingen: Wallstein, 2014), 217-258.

56 Abraham Geiger, Plan zu einem neuen Gebetbuche nebst Begründungen (Breslau: Schletter'sche Buchhandlung, 1870), 5; Israelitisches Gebetbuch für den öffentlichen Gottesdienst im ganzen Jahre. Im Einverständnisse mit der Gemeinde-Verwaltung in Frankfurt am Main, Erster Theil (Berlin: Gerschel, 1870), VII; Geiger, Etwas über Glauben und Beten, 46.
} 
Wo Bedarf zur Umgestaltung bestand, wusste Geiger insbesondere in seinem Plan für ein neues Gebetbuch in Frankfurt am Main (1870) konkret zu benennen. Seine Leitlinien zur Reform des Siddur zielten auf verschönernde Maßnahmen, nahmen aber vor allem theologische Revisionen der Liturgie vor, die sich vornehmlich auf die jüdische Gottesidee sowie das Verhältnis Gottes sowohl zu Israel als auch zur übrigen Menschheit bezog. Anthropomorphismen, die sich namentlich in den liturgischen Dichtungen des Mittelalters (Piyyuțim) fanden, galt es ebenso zu beseitigen wie angelologische Vorstellungen sowie Erinnerungen an den Opfer- und Priesterkult. Der Glaube an die Unsterblichkeit sollte materielle Vorstellungen einer leiblichen Auferstehung der Toten in den Hintergrund rücken, um stattdessen die Idee einer unvergänglichen Seele hervorzuheben. Mit der Suche nach einer bürgerlichen jüdischen Konfessionalität ging zudem eine universale Umdeutung des Auserwähltseins Israels einher, das Geiger weniger als göttliche Bevorzugung und Absonderung eines Volkes denn als weltgeschichtlichen Auftrag an eine Religionsgemeinschaft zur Bezeugung, Verkündung und Verbreitung des Gottesglaubens auslegte. Göttliche Gnadenerweisungen durften sich somit nicht auf die Juden beschränken, sondern schlossen die gesamte Menschheit ein. Erteilte Geiger jeglichem Partikularismus der Juden eine Absage, dann mussten auch alle ethnisch-religiösen Zukunftshoffnungen in den Hintergrund rücken. Dazu zählten der Glaube an einen persönlichen Messias, das Heilsversprechen einer Sammlung der Zerstreuten in Zion oder die Hoffnung auf die Neuerrichtung des Tempels als Nationalheiligtum. So gesehen, bezeichneten Gebete für die Wiederherstellung Jerusalems, als „eine[r] durchaus gleichgültige[n] Stadt“, keine religiöse Tat, sondern vielmehr „eine Gotteslästerung““. ${ }^{57}$

\section{Resümee}

1854, kurze Zeit vor seiner Emigration nach Baltimore, veröffentlichte Reformrabbiner David Einhorn (1809-1879) seine Schrift Princip des Mosaismus, die er als Beitrag zu einer systematischen Darstellung des jüdischen Glaubens verstanden wissen wollte. Im Kontext dieses Aufsatzes aufschlussreich ist insbesondere das Vorwort des Buches, in dem der Autor seine Unzufriedenheit mit der jüdisch-theologischen Literatur seiner

57 Geiger, Etwas über Glauben und Beten, 53 et passim; idem, Plan zu einem neuen Gebetbuche, 5-7; vgl. auch idem, „Nothwendigkeit und Maass“, 207-209; Klaus Herrmann, „Liberale Gebetbücher von ,Die Deutsche Synagoge“ bis zum ,Einheitsgebetbuch““, in Liturgie als Theologie. Das Gebet als Zentrum im jüdischen Denken, hrsg. von Walter Homolka (Berlin: Frank \& Timme, 2005): 84 f.; K. Koltun-Fromm, „Historical Memory in Abraham Geiger’s Account of Modern Jewish Identity“, in Jewish Social Studies 7.1 (2000): 121-123; Jakob J. Petuchowski, Prayerbook Reform in Europe. The Liturgy of European Liberal and Reform Judaism (New York: World Union for Progressive Judaism, 1968), passim; allgemein zum jüdischen Messianismus in der Neuzeit: George Y. Kohler, Hrsg., Der jüdische Messianismus im Zeitalter der Emanzipation. Reinterpretationen zwischen davidischem Königtum und endzeitlichem Sozialismus (Berlin und Boston: de Gruyter, 2014). 
Gegenwart zum Ausdruck brachte. Einhorn glaubte eine grundsätzliche Fehlentwicklung der wissenschaftlichen Kritik zu erkennen, die nämlich „eine einseitige und rein negative Stellung“ einnehme, indem sie

sich die Aufgabe gestellt [habe], zu zeigen, was das Judenthum nicht ist, und in dieser Hinsicht allerdings höchst beachtenswerte Materialien geliefert; auf die Frage aber, was das Judenthum ja sei, ist sie die Antwort bis auf die Stunde schuldig geblieben. ${ }^{58}$

Darüber, ob Einhorn auch Abraham Geiger in den Tadel einschloss, lässt sich nur mutmaßen. Immerhin fußte seine Beurteilung auf Beobachtungen, die auch auf seinen Kollegen und langjährigen Weggenossen zutrafen. ${ }^{59}$

Gewinnt man eine Anschauung davon, wie nachhaltig seine religionsgeschichtlichen Forschungen die traditionelle jüdische Glaubenswelt erschütterten, dann mag Geigers Argument überraschen, dass Fragen der systematischen Theologie im Streit der Gegenwart um die Modernisierung des Judentums allenfalls eine Nebenrolle spielten:

Nicht ob die Welt aus Nichts geschaffen, nicht ob unmittelbare oder mittelbare Offenbarung anzunehmen sei, nicht ob Wunder geschehen oder nicht, ob Glaubenssätze in ihrer Strenge anzunehmen sind oder nicht, ist der wesentliche Differenzpunkt, wenn dieser auch manchmal auf der einen oder andern Seite mit hineinspielen mag. ${ }^{60}$

In das Zentrum seiner Kritik am gesetzestreuen Judentum stellte er dessen Orthopraxie, der er eine genuine Frömmigkeit des progressiven Judentums gegenüberstellte. „Legalität“ und „Formglauben“ beschrieben demnach eine konservative religiöse Praxis, der er zum Vorwurf machte, die Gültigkeit des jüdischen Regelkatalogs aus der normativen Kraft der Vergangenheit abzuleiten, ohne die Gebote auf ihr religiöses Moment hin zu befragen. Die „Gesetzlichen“ huldigten also einer theonomen Willkür und forderten eine blinde Unterwerfung, die mit der Vorstellung der Vollkommenheit Gottes im Widerspruch stehe. Echter Gottesgehorsam hingegen bezeichne eine Geisteshaltung, die das sittliche Bewusstsein als Göttliches im Menschen zum Maßstab des Handelns erhob. Aus dieser Sicht besaß die Geschichte auch die Macht, der

58 David Einhorn, Princip des Mosaismus und dessen Verhältniß zum Heidenthum und rabbinischen Schriftthum, Erster Theil (Leipzig: Verlag von E. L. Fritzsche, 1854), 6f.; weitere Teile sind nicht erschienen.

$59 \mathrm{Zu}$ Geiger und Einhorn siehe Christian Wiese, „Heros, Ikone, Gegenbild: Abraham Geiger aus der Perspektive der Reformbewegung in Amerika“, in Jüdische Existenz in der Moderne, hrsg. von Wiese, Homolka und Brechenmacher, 213-242; sowie Michael A. Meyer, „German-Jewish Identity in Nineteenth-Century America“, in idem, Judaism within Modernity: Essays on Jewish History and Religion (Detroit: Wayne State Univ. Press, 2001): 335-337.

60 Geiger, „Die letzten zwei Jahre“, 28. 
Subjektivität jedes Zeitalters durch Veränderungen der religiösen Form Rechnung zu tragen. ${ }^{61}$

Paradigmatisch für Geigers ethischen Monotheismus stand dessen Auslegung der biblischen Erzählung von der 'Aqeda, der Bindung Isaaks, in der er die Erkenntnis der Unstatthaftigkeit des Menschenopfers nicht aus einer situativen Zuwendung Gottes, sondern aus der tieferen religiösen Einsicht Abrahams ableitete. Das Verdienst des biblischen Patriarchen wollte er gerade nicht in dessen Bereitschaft erkennen, einem göttlichen Befehl Folge zu leisten und den eigenen Sohn darzubringen. Der religiöse Fortschritt liege im Gegenteil darin begründet, dass der biblische Patriarch diese Versuchung, dem Beispiel der götzendienerischen Umwelt $\mathrm{zu}$ folgen, überwunden habe - in der geläuterten Einsicht, dass Gott ein solches Opfer niemals verlangen würde. ${ }^{62}$

1839 publizierte Geiger seinen Aufsatz über „Die zwei Betrachtungsweisen“, in dem er die theoretische Arbeit des theologischen Schriftstellers und die praktische Wirksamkeit des Rabbiners gegenüberstellte. Dabei beschrieb er den Schriftsteller als unbequemen Mahner, dessen scheinbare Lust an der Zerstörung aber der Aufgabe geschuldet sei, die religiösen Ideen gegen das Übergewicht der Religionspraxis zur Geltung zu bringen. ${ }^{63}$ Es mag daher nicht überraschen, dass solche Textpassagen, in denen Geiger positive Auskünfte zu den theologischen Grundlagen des jüdischen Glaubens erteilte, vor allem in dessen praktische Theologie eingebettet sind, in der die zeitgenössische Auffassung der religiösen Ideen zum Ausdruck kommen konnte. Es ist freilich bedauerlich, dass der talentierte Kanzelredner seine Predigten in der Regel nicht im Druck veröffentlichte. ${ }^{64}$ Knappe, aber prägnante Aussagen zu den wesenhaften Grundlagen des jüdischen Glaubens in der Gegenwart finden sich in den Jahresberichten der jüdischen Religionsschule in Breslau, als deren Leiter Geiger 1846 die religiösen Prinzipien erläuterte, von denen sein Unterricht ausging:

[...] und zwar 1. von dem Glauben an den einzigen heiligen Gott; 2. von dem Glauben, dass der Mensch eine höhere Würde, einen denkenden Geist, der ihn belebt, eine unsterbliche Seele besitzt, d.h. in dem Ebenbilde Gottes geschaffen ist, und endlich, 3. dass ein jeder einzelne Mensch in Verbindung mit allen übrigen zu dem hohen Ziele der Vervollkommnung der Gesammtmenschheit mitzuwirken habe, dass die Menschheit berufen sei, dem Ideale der gegenseitigen Verbrüderung, der Herrschaft der Gerechtigkeit, der Liebe und des Friedens immer entgegenzu-

61 Idem, „Die Rabbinerzusammenkunft. Sendschreiben an einen befreundeten jüdischen Geistlichen“, in Wissenschaftliche Zeitschrift für jüdische Theologie 3 (1837): 317 f.; idem, „Der Formglaube in seinem Unwerthe und seinen Folgen (aus der Wissenschaftlichen Zeitschrift für jüdische Theologie 1839)“, in Abraham Geiger's Nachgelassene Schriften, hrsg. von Geiger, Bd. 1, 483-487; siehe auch „Geiger an Dernburg, 23. Februar 1836“, in „Abraham Geigers Briefe“, 115.

62 Geiger, Etwas über Glauben und Beten, 41-43; Vogelstein, Systematische Theologie, 272-274.

63 Abraham Geiger, „Die zwei verschiedenen Betrachtungsweisen“, 323-332.

64 Vgl. „A. Geiger an M.A. Levy, 2. September 1870“, in Abraham Geiger's Leben in Briefen, hrsg. von Geiger, 332; siehe aber idem, „Gottesdienstlicher Vortrag gehalten in der grossen Synagoge zu Breslau am Sabbathe Matthot Massé 5598 (21. Juli 1838)“, in Abraham Geiger’s Nachgelassene Schriften, hrsg. von Geiger, Bd. 1, bes. 364 . 
streben, was der wahrhafte Gedankenkern des richtig verstandenen Messiasglaubens ist. Aus diesen Sätzen, der Einheit Gottes, der Gottähnlichkeit des Menschen, der Hoffnung auf die in Liebe vereinte Menschheit, welche überall in der heiligen Schrift wiederhallen, ergeben sich auf ganz einfache Weise die Pflichten gegen Gott, gegen uns selbst und gegen die Mitmenschen; sie sind die unerschütterlichen Grundlagen, welche das ganze Gebäude des religiösen und sittlichen Lebens tragen. ${ }^{65}$

Der systematische Ertrag dieser Erläuterungen ist zugegebenermaßen gering. Die wissenschaftliche jüdische Theologie, zu der sich Geiger enthusiastisch bekannte, konnte im Grunde nur religionsgeschichtliche Erkenntnisse zu Tage führen, musste aber die Antwort auf absolute religiöse Wahrheiten weitgehend schuldig bleiben. In seinen populären Vorträgen zur Frühgeschichte des Judentums, die er in den 1860er Jahren zunächst vor einem gebildeten Frankfurter jüdischen Publikum hielt, brachte Geiger auch begeisterte Beschreibungen der jüdischen Glaubenswelt, die er allerdings nicht als systematische Darstellung der geltenden Lehre präsentierte, sondern eben als historische Schilderungen eines ethischen Monotheismus, der in der Auseinandersetzung mit seiner heidnischen Umgebung in die Welt trat. ${ }^{66}$ Gegenüber seinem Sohn Ludwig räumte Abraham Geiger 1866 freimütig ein, dass für die Grundlagen des Judentums (,Gott, unsterblicher Menschengeist, Willensfreiheit, sittliche Anforderung und Veredlung“) kein Beweis erbracht werden könne, diese aber dem menschlichen Bedürfnis nach Transzendenz Rechnung trugen und auch in der Zukunft universale Anerkennung beanspruchten. Seine Skepsis bezog sich also nicht allein auf die religiösen Wahrheiten selbst, sondern damit einher ging eine Zurückhaltung, die eigene Konfession in Wort und Schrift nach außen zu tragen. Belehrung über Glaubensinhalte mochte in der Kindererziehung probates Mittel sein, um die Grundlagen einer religiösen Identität der Heranwachsenden zu befestigen. Aufgabe und Freiheit jeder/ jedes erwachsenen Gläubigen war es aber, in der Kenntnis der jüdischen Religionsgeschichte die Bestätigung und konkrete Form der religiösen Ideen in sich selbst zu finden. Seiner Generation schrieb Geiger zugleich das Verdienst zu, diese Freiheit einer liberalen Anschauung des Judentums mühevoll errungen zu haben. Von einer solchen subjektiven Warte aus betrachtet, hatte die jüdische Theologie eine Gegengeschichte präsentiert und mit dieser die wissenschaftlichen Waffen für einen Befreiungskampf bereitgestellt, in dessen Verlauf die Orthodoxie ihren Hegemonialanspruch aufgeben musste. Das Reformjudentum trug einen Sieg davon, den Geiger aber durchaus nicht als Gelegenheit verstanden wissen wollte, eine progressive Fassung des jüdischen Glaubens auf Dauer normativ festzulegen. ${ }^{67}$

65 Geiger, „Abhandlungen aus den Programmen der jüdischen Religionsunterrichtsanstalt“, 323f. 66 Abraham Geiger, Das Judenthum und seine Geschichte bis zur Zerstörung des zweiten Tempels. In zwölf Vorlesungen, 2. Aufl. (Breslau: Schletter, 1865), 20 - 23.

67 „A. Geiger an Ludwig Geiger, 14. Januar 1866“, in Abraham Geiger, hrsg. von Geiger, 179f. 
